\title{
THE LEVEL OF DEPRESSION, ANXIETY, STRESS AND COPING STRATEGIES IN PARENTS WITH CONGENITAL TALIPES EQUINOVARUS CHILDREN
}

Mohd Shukrimi bin Awang ${ }^{1}$, Ardilla Hanim bt Abdul Razak ${ }^{1}$, Nurazlina bt Azizi ${ }^{1}$, Nur Amalina Syazwani bt Bukhori ${ }^{1}$, Hanisah bt Mohamad Zainuddin ${ }^{1}$ and Nora bt Mat Zin

${ }^{1}$ Kulliyyah of Medicine, International Islamic University of Malaysia, Kuantan, Pahang, Malaysia

Presenter: Nurazlina bt Azizi, nurazlina.azizi@gmail.com

Introduction: Having children with congenital anomalies, particularly congenital talipes equinovarus (CTEV) may impact the psychological wellbeing of the parents. This study is to assess the psychological impact of CTEV, the related factors, and the coping strategies used by the parents in Hospital Tengku Ampuan Afzan (HTAA), Kuantan, Pahang.

Materials and method: A cross-sectional study involving 43 parents with CTEV child was conducted from 18 July till 27 August 2016 at Hospital Tengku Ampuan Afzan. Selfadministered Malay version of Depression Anxiety and Stress Scale 21 items (DASS-21)1 is used to measure the psychological wellbeing of the parents and the Malay version of Brief COPE is used to measure coping strategies. Data were analysed using frequencies, percentages and Chi-square $\chi 2$ test.

Results: There were 43 respondents, majority were Malay $(90.7 \%)$, female $(86 \%)$, and married $(97.7 \%)$. Average age was 30.3 years old. $70 \%$ of the respondents were having a positional CTEV child and 30\% have structural CTEV. Overall, prevalence of depression, anxiety, and stress among parents were very low. Only $9.3 \%$ experience depression, $11.6 \%$ experience anxiety, and only $2.3 \%$ was reported to be stress. The psychological wellbeing of the parents was not related with the parental age, gender, marital status, education level, and monthly income. The most common coping strategy used is religion, acceptance and positive reinterpretation.

Conclusion: Only a few parents with structural and positional CTEV reported symptoms of depression, anxiety, and stress and most of them use positive coping strategies such as religion, problem focused and dysfunctional focused. 